\title{
MEDIA PORTRAYAL OF ALCOHOL DOES NOT MATCH ITS REAL HARM EFFECTS IN THE CZECH REPUBLIC
}

\author{
Kateřina Zachová, Benjamin Petruželka, Miroslav Barták, Vladimír Rogalewicz \\ Department of Addictology, First Faculty of Medicine, Charles University, Prague, Czech Republic
}

\section{SUMMARY}

Objectives: The Czech Republic ranks among countries with the highest alcohol consumption per capita. Several older studies discuss Czech media portrayal of health effects of alcohol, but we found no recent analysis of media portrayal of harms caused by alcohol consumption. Our analysis aims to fill this gap in.

Methods: The dataset of texts $(n=903)$ consisting of articles from press, radio, television and the internet published within a 30-day interval in 2017 (Newton Media computerized database) was coded and analyzed using mixed quantitative and qualitative approach to content analysis. The frequency of references to acute and long-term alcohol harms of various types were counted, and the results were compared to the classification of (alcohol) harms by the Independent Scientific Committee of Drugs (ISCD).

Results: The short-term intoxication effects in the areas of crime and road safety, in particular reports on traffic accidents, are over-represented, while topics describing the impact of alcohol use on health, family and society, as well as economic costs or environmental issues seem to be marginal. That corresponds to the fact that police and courts were the information source in more than half of the articles, while information sourced from physicians, sociologists and drug field professionals was rather scarce.

Conclusions: Media portrayal of the harms caused by alcohol use does not match up to real harm effects on the society. In terms of public health, it is imperative to strengthen media presentation of the impact of alcohol use on health and social issues.

Key words: media coverage, media analysis, alcohol use impact, acute intoxication effects, long-term use effects, Czech Republic

Address for correspondence: K. Zachová, Charles University, First Faculty of Medicine, Department of Addictology, Apolinářská 4, 12800 Praha 2, Czech Republic. E-mail: Katerina.Zachova@lf1.cuni.cz

https://doi.org/10.21101/cejph.a5826

\section{INTRODUCTION}

Alcohol use is widely acceptable in the Czech cultural background even though it is the leading cause of harm among all addictive substances. High consumption of alcoholic beverages is one of the major risk factors negatively affecting the quality of health, mortality and morbidity (1). The Czech population has long been considered within the European Union as one of the largest consumers of alcohol per capita (2). According to a National Institute of Public Health research report, up to $20 \%$ of the Czech adult population show risky patterns of alcohol use or are in the risk of alcohol addiction (3).

Despite all the negative impacts and documented harmfulness of alcohol use, attempts to regulate its consumption more strictly are often impeded by a misconception among a large part of the general public. One reason for this is the limited knowledge about the risks associated with patterns of drinking and with current volume of alcohol consumption (1).

Improved public health is one of the long-term strategic goals (not only) of the Czech health policy $(4,5)$. To influence the public on such a sensitive issue as reducing alcohol consumption, it is important to raise general awareness in this area (6).
Alcohol is firmly embedded in the awareness of people of all ages as a common part of everyday life, whether with positive or negative connotations (7). Unlike other addictive substances, the existence of alcohol is constantly present, especially in traditional news media $(8,9)$. The media theories are not providing us with simple answer what is the influence and what are the roles of mass media in public health communication (10) and this discussion is beyond the scope of this article. However, it is plausible to work with the assumption that news is significant in shaping the "climates of opinion" towards alcohol or in articulating shared cultural values around alcohol (11-13). Thus, in order to design effective global alcohol prevention programmes, it is important to focus on what information and in what context is currently presented in the media (14).

The scientific community has shown a considerable interest in media analysis, using several different approaches, including political economy (15), public policy (16), and alcohol marketing (17). Studies often focus on the presentations of alcohol in relation to the types of analyzed media (18) and taking into account the target groups of readers (17). Sometimes they focus on specific groups such as children, young adults (19), or alcohol consumption during pregnancy (20). Other authors are involved 
in analyzing certain types of media (social media, newspapers) (21) or policy initiatives such as the minimum unit pricing (22), advertising (23), deaths related to alcohol (6), or long-term implications of media reporting on alcohol (24). The construction of discourse has been analyzed by Hansen and Gunter (25). At a national level, the issue was studied by Lemmens et al. (26) in the United States, by Azar et al. (27) in Australia, or by Nicholls (13) in the United Kingdom. However, next to two diploma theses describing the situation more than ten years ago $(28,29)$ and some brief statistics from the National Monitoring Centre for Drugs and Addiction $(30,31)$, we have not found any study on alcohol portrayal in the Czech Republic.

From the public health perspective and in the Czech context the most important topic for an analysis of news about alcohol is what information about alcohol and its related harms as well as individual and societal consequences are published by the media (5). This means determining to what extent does the attention paid to various harm types corresponds to their real gravity for society. We decided to base our comparison on an expert analysis as it would be beyond the scope of this study to gather and to weight real data from a corresponding period.

Various approaches to classify types of harm related to alcohol (and drug) usage were listed and explained by Mravčík (32). It is the categorisation used by the Independent Scientific Committee of Drugs (ISCD) (33) that matches up best to our purposes. They classify and evaluate harm according to 16 criteria that map a whole range of possible problems associated with the use of addictive substances. The types of harm are clustered into groups according to the impact on mental faculties, somatic symptoms and/or social behaviour, and divided into two levels according to their action (to the users, to others). The ISCD assigned each addictive substance (alcohol, heroin, cocaine, tobacco etc.) a set of 16 values or weights reflecting the severity of each type of harm. A higher weight corresponds to its higher harmfulness. Other similar classifications by other authors either covered less categories of harms (34-36), or they went into deeper details than a media analysis could provide $(37,38)$. That is why we refer to the ISCD classification for our comparison.

The main objective of this paper is to investigate what types of harm related to alcohol use are presented by the Czech media and what types are emphasized. The other objective is to compare the obtained frequencies of alcohol related types of harm with the severity of each of these harm types, and, last but not least, to describe the characteristics of the media portrayal of alcohol in the selected period.

\section{MATERIALS AND METHODS}

The dataset was coded using the 'qualitative content analysis' (39), although the consequent statistical steps could be also seen as mixed 'quantitative-qualitative content analysis' in terms of Bryman's classification (40). In order to address our primary aim (i.e. to match the gravity of various alcohol harm aspects to the attention paid to them by the media), values related to alcohol related harms were retrieved from the literature and compared with the data obtained from our dataset. We chose the ISCD classification (33), as it matches up to our needs the best way: it has a structure directly applicable to categorize alcohol usage effects and it explicitly weights all types of alcohol harms. Thus, we compared the frequency of each harm type in Czech media to its severity according to this classification system.

\section{Dataset Characteristics}

A dataset of 903 articles published between 17 September and 18 October 2017 was selected for the analysis of the media portrayal of alcohol. It consists of transcripts of all television and radio news and programmes as well as articles from printed and internet periodicals. Articles were retrieved from the Newton Media database (41), their selection was subject to the occurrence of the word alcohol and addiction combined with at least one of the following words or phrases: price, intoxication, traffic accidents, crimes, violence, damage, aftermath, pub, beer/winel vodka/rum, party, breath test, limitation, checks, health, drinking, entertainment, children, addiction.

Advertisements and commercials were not included into the selection. The selected period was chosen by a purposive sampling method in the lower risk part of the year in terms of alcohol consumption in the Czech Republic (42).

\section{Coding Procedure}

The data were coded following the Manual for Coding of Media Messages on Addictive Substances and Related Issues: User's Handbook (43). During the processing of the first 100 articles, the coding system was adapted for specific needs of the current study (in order to narrow the addictive substance focus to alcohol only). The main coding method differences against the coding manual adopted during the preparatory phase were made in this sense:

We added the categories media range, death, occurrence of other (addictive) substances, and we skipped the category drug in the heading. Unlike the manual that worked with bigger amount of details, we aggregated several similar and less frequent values. We refined some content inside other categories as well. For example, we added police spokesperson and physician to the information sources, we added road control and traffic accident to the orientation/ topic, and we added self-harm to the role of alcohol. More changes were made in the category criminal act: we added inebriation, breath test refusal, home violence, threatening with defective foods, for example. In the categories of harm we added the variables victimization of user, foetus jeopardy, combination of bio-psycho-social harm. These adjustments slightly limit the possibility of direct comparison of our results to similar earlier studies $(28,29)$ while, at the same time, they allow us to better explain certain results.

\section{Measures}

The descriptive characteristics for all articles from our dataset were coded using 25 variables listed below:

- Seven variables map the basic characteristics of the media and of the article: media range (global, regional); media type ( $\mathrm{TV}$, radio, printed media etc.), type of information source (police, drug specialist etc.); traceability of the information source (exactly specified, possible to find etc.); genre (news, journalism etc.); article form (report, interview etc.); article orientation (alcohol, other topic etc.).

- Five variables describe the users, the scene, and any addictive substances mentioned in the article: alcohol type (beer, wine 
etc.); occurrence of other substances (tobacco, medicaments, opioids etc.); users (child, family member, homeless, politician, celebrity etc.); gender of users (male, female, both); user scene (usage trends, production or usage of alcohol etc.).

- Eight variables, the key variables for our study, cover the effects of alcohol use and the emotional evaluation of alcohol: effects of long-term use (health problems, addiction, foetus jeopardy etc.); effects of acute intoxication (road safety, crime, health issues etc.); role of alcohol (enjoyment, market, stigmatization etc.); focus/topic (primary prevention, users story, roadside inspection etc.); emotional assessment of the article's content (positive, neutral, negative), emotional quality of the heading (positive, neutral, negative), crime or delict type (home violence, endangering through harmful food, alcohol served to youngsters etc.); death (death of a specific person, death or risk of death mentioned in general terms, no reference to death).

- The remaining five variables map complementary circumstances: heading adequacy (yes, no); children mentioned in relation to alcohol (yes, no - note: this did not necessarily refer to the alcohol user e.g. in cases as "child was present in a crashed car"); international focus (national, international, both), well-known persons (explicit names of commonly known personalities like the president of CR, celebrities, authorities, national drug coordinator etc.); pictorial attachment (photo, illustrative photo, nothing).

\section{Mapping Our Dataset to 16 ISCD Harm Criteria}

In order to match up the 16 harm criteria of the ISCD classification to our dataset we determined which values from which of our categories describe them. There was typically a direct correspondence to one of the acute or long-term alcohol use effects (Table 1). In some cases, we had to combine more variables, namely when we excluded articles with emotionally positive content to prevent counting alcohol benefits into harm. Some harm criteria mapped to values that originally existed in our classification system, however, that did not apply to any article from our dataset. These types of harm were not mentioned in the examined media. Some values (e.g. death, victimization, and the combination of social and psychosomatic consequences) finally required to review all the related articles and to map them to the ISCD criteria manually.

\section{Distinguishing Benefits from Harms}

In our dataset, alcohol use effects were coded in two variables (acute intoxication effects, effects of long-term usage). These effects were mostly negative (harm), but in positive effects (benefits) were detected. We used a combination of two other variables some exceptional cases $(n=9)$ also (role of alcohol, emotional assessment of the article's content) to identify these cases and to exclude them from the above-mentioned mapping.

\section{Counting Harm References in Dataset}

Only reports mentioning either acute intoxication effects or effects of long-term alcohol use were subject to our mapping $(\mathrm{n}=540)$. To get the total count of harm references $(\mathrm{n}=596)$ we subtract the nine exceptions (benefits) and we count twice articles that mentioned both types of effects $(n=65)$. These were

Table 1. Mapping Independent Scientific Committee of Drugs (ISCD) harm classification to our measures (acute intoxication effects, long-term alcohol use effects)

\begin{tabular}{|l|l|}
\hline ISCD harm evaluation criteria & Corresponding acute/Long-term effect \\
\hline Drug-specific mortality & Acute: death* \\
\hline Drug-related mortality & Long-term: death* \\
\hline Drug-specific damage & Acute: health problems \\
\hline Drug-related damage & Acute: victimization*; Long-term: health problems \\
\hline Dependence & Long-term: dependence \\
\hline Drug-specific impairment of mental functioning & Acute: psychic effects \\
\hline Drug-related impairment of mental functioning & Long-term: psychic effects \\
\hline Loss of tangibles** & Long-term: social problems \\
\hline Loss of relationships & Acute: social problems \\
\hline Injury & Acute: traffic incidents; Long-term: foetus jeopardy \\
\hline Crime & Acute: criminal activity; Long-term: criminal activity \\
\hline Environmental damag* & Long-term: environmental damage \\
\hline Family adversities & Long-term: social problems \\
\hline International damage & Long-term: international damage \\
\hline Economic cost & Acute: negligent harm \\
\hline Community & Long-term: community damage \\
\hline
\end{tabular}

${ }^{*}$ Articles related to death (15), victimization (11), social problems (29) and to the combination of social and psychosomatic consequences (21) were reviewed and mapped to the ISCD harms manually.

${ }^{* *}$ Four harm types: loss of tangibles, environmental damage, international damage, and damage to communities had their primary direct equivalents in our classifications but these were empty. We have combined other variables to detect potentially more articles on these topics, however, after individual revision, almost none of them qualified for the harm criteria at the end. 
often longer articles discussing alcohol harms in a more complex way, and therefore typically counted both in the category harm to users - psychological - dependence and in the category harm to others - social - crime. Articles that did not mention acute intoxication effects or effects of long-term alcohol use $(\mathrm{n}=363)$ were excluded from mapping.

\section{Comparing Harm Reference Frequency to Real Harmfulness}

In order to be able to compare the ISCD scoring of harm types and the frequency of references to short-term and/or long-term alcohol harm references in Czech media - we have converted both to percentages. This means that in the former case we expressed the weighted score of alcohol for each criterion as a percentage of the total of 72 , i.e. of the cumulative weighted score of all 16 criteria for alcohol. In the latter case we expressed the absolute number of times a specific harm was mentioned as the main short-term and/or long-term effect of alcohol usage as a relative percentage of the total count of harm references $(n=596)$ in our dataset $(n=903)$.

\section{RESULTS}

\section{General Characteristics of Articles}

The general classification of all articles $(n=903)$ showed that the dataset consisted of 467 articles published in local media, while media with nationwide coverage accounted for 436 titles. The dataset was dominated by news from the Internet $(n=558)$ and from printed media $(n=286)$. Fewer articles were from television $(n=41)$ or radio $(n=18)$. The way the media spoke about alcohol did not differ significantly from one media type to another. The only exception was radio that was more health-oriented. One quarter of the articles had alcohol as the main subject $(n=223)$, while more often $(n=404)$ it was mentioned marginally. In 276 articles alcohol played a significant role, although the basic topic was different (e.g. articles about celebrities, reports of misdemeanours, and court reports). The news was mostly presented in the form of a brief news report $(\mathrm{n}=825)$ as opposed to an interview, poll, review, answer $(n=78)$. The genre of informative news $(n=690)$ prevailed over journalism, advertisements, and others $(n=213)$. The neutral value of emotional assessment of article content $(n=475)$ dominated the articles. Articles related to alcohol and its effects in a negative way $(\mathrm{n}=398)$ considerably outnumbered the positive ones $(n=30)$ (Table 2). Reporting on alcohol problem in the transnational context was quite insufficient.

\section{Sources of Information}

Explicitly specified/traceable information sources were mentioned in 628 articles, while vague sources $(n=111)$ and missing sources $(n=164)$ were less frequent.

In most articles, the main information source were various representatives of the state criminal-justice bodies $(n=551)$ as police and/or court. This was particularly due to a high number of explicitly named police spokespersons $(n=440)$, (who made two thirds of all explicitly specified/traceable information sources).
Substantially fewer articles were based on expert sources from the fields of health care and/or drug issues $(n=127)$. Out of these, 62 cases quoted the National Drug Coordinator who was mentioned in connection with two widely publicized events at the time: a proposal to increase the tax on alcohol, and national actions to reduce alcohol consumption by minors. Among healthcare experts, 18 were physicians. Few reports drew information directly from alcohol consumers $(n=10)$ and/or persons from the user's neighborhood $(n=24)$. Alcohol manufacturers and resellers were in the absolute minority, which corresponds to the fact that advertisements and commercials were excluded from the dataset. A big disparity (24:1) between police spokespersons $(n=440)$ and physicians $(\mathrm{n}=18)$ appeared in the results.

\section{Context Referring to Alcohol}

The analyzed dataset contained mostly police reports (the category type of information source). Traffic accidents $(n=333)$ created one third of the commented affairs. Roadside inspections ( $n=115)$ were quite numerous mostly reporting positive or negative results of breath alcohol testing. Hence, traffic reporting accounts for half of all analyzed articles $(n=448)$. The third most numerous part included police reports that did not concern traffic issues $(n=100)$, e.g. police interference with intoxicated persons.

Little attention was paid to prevention (primary $n=40$, secondary $n=15$, tertiary $n=1$ ). Drug scene that connects the use of alcohol with the use of other types of addictive substances was almost unreported $(n=3)$. More attention was paid to information on alcohol as a substance $(n=39)$. Among them only few articles $(n=8)$ represented alcohol as benefit or a part of everyday life, for example recipes to improve cooking or instructions how to drink alcohol hard with minimum aftermath.

\section{Role of Alcohol}

Role of alcohol was specified in 646 articles, while negative roles prevailed over neutral ones. More than half of the reports $(n=513)$ described alcohol as the cause of negative outcomes or events. Criminal activities, violence $(n=290)$ that the perpetrator committed under influence of alcohol were clearly dominating; one third of the articles reported traffic accidents $(n=106)$. Situations in which alcohol user was threatening his/her surroundings were reported many times more often than situations in which the user was victimized after consumption of alcohol $(n=8)$. The latter included especially the cases when the users were attacked in public or hit by a car. Somatic and mental health aspects (health threats and addiction, illness, $\mathrm{n}=175$ ) were also present quite frequently, and clearly prevailed over social and societal constraints (society threats and limitation, stigma, $n=20$ ). Alcohol in the context with goods, market $(n=75)$ occurred mainly in the discussion of the proposal to increase the tax on the sale of alcoholic beverages.

\section{Portrayal of Alcohol Use Effects}

Effects of alcohol use were mentioned in most of the analyzed articles $(n=540)$ generally with negative connotations. The acute intoxication effects $(n=411)$ were twice as frequent as long-term 
Table 2. Role of alcohol and emotional assessment of an article's content $(N=903)$

\begin{tabular}{|c|c|c|c|c|c|}
\hline \multirow{2}{*}{\multicolumn{2}{|c|}{ Role of alcohol }} & \multicolumn{3}{|c|}{ Emotional assessment of an article's content } & \multirow{3}{*}{$\begin{array}{c}\text { Total } \\
257\end{array}$} \\
\hline & & \multirow{2}{*}{$\begin{array}{c}\text { Negative } \\
2 \\
\end{array}$} & \multirow{2}{*}{$\begin{array}{c}\text { Neutral } \\
255\end{array}$} & \multirow[t]{2}{*}{ Positive } & \\
\hline Unspecified & (0) & & & & \\
\hline Enjoyment & $(+)$ & 3 & $8^{*}$ & $14^{*}$ & 25 \\
\hline Freedom, status, style & $(+)$ & 6 & $5^{*}$ & $7^{\star}$ & 18 \\
\hline Goods, market & (0) & 32 & 40 & 3 & 75 \\
\hline Substance, research & (0) & 9 & 13 & 2 & 24 \\
\hline Limitation, stigma & $(-)$ & 3 & 1 & & 4 \\
\hline Health threats & $(-)$ & 69 & 19 & 1 & 89 \\
\hline Addiction, illness & $(-)$ & 66 & 20 & & 86 \\
\hline Society threats & $(-)$ & 12 & 3 & 1 & 16 \\
\hline Crime, violence & $(-)$ & 180 & 108 & 2 & 290 \\
\hline Bad habit & $(-)$ & 8 & 3 & & 11 \\
\hline Victimization & $(-)$ & 8 & & & 8 \\
\hline Total & & 398 & 475 & 30 & 903 \\
\hline \multicolumn{5}{|c|}{ *Emotionally positive articles skipped when comparing with ISCD harm scores } & $34^{*}$ \\
\hline \multicolumn{5}{|c|}{ Remaining articles - subjected to a further comparison with ISCD harm scores } & 869 \\
\hline
\end{tabular}

use effects $(n=194)$ with 65 cases reporting both types of effects simultaneously. Neither acute nor long-term effects of alcohol use were often the case as well $(n=363)$, typically in articles on traffic accidents where breath test proved that the driver did not drink alcohol.

The most frequent value in both categories of alcohol usage effects was criminal activity as the effect of acute intoxication $(n=227)$ followed by articles on traffic accidents $(n=113)$. Their frequency significantly dominated over others. Values addiction $(n=57)$ and health problems $(n=53)$ prevailed among the long-term use effects. Some values, such as material damage, community damage, environmental damage, international damage or political destabilization did not appear in articles in either category (Table 3 ).

\section{Comparison of Media Portrayal of Alcohol Use Ef- fects to ISCD Categorization}

According to the ISCD, the most significant harms result from direct and indirect economic costs of alcohol (including e.g. police, healthcare, social services or prison costs). The harm score is $17.7 \%$. In Czech media, these issues occurred only in $0.2 \%$ of all analyzed reports. Here is the major disproportion (Fig. 1). The second most serious negative effect of alcohol drinking with the score of $16.0 \%$ is injury (the psychological and somatic impact on the user's surroundings). It encompasses not only various types of violence that often turns against the user's own family and/or children, but also health and psychological consequences (e.g. in road accidents). This aspect occupies the second place in Czech media according to their frequency $(19.3 \%)$.

Table 3. Acute intoxication effects and long-term usage effects $(N=903)$

\begin{tabular}{|l|c|l|c|}
\hline Acute intoxication effects & $\mathbf{n}(\%)$ & Long-term usage effects & $\mathbf{n}(\%)$ \\
\hline Unspecified & $492(54.5)$ & Unspecified & $709(78.5)$ \\
\hline Health problems & $23(2.5)$ & Health problems & $53(5.9)$ \\
\hline Psychic effects & $12(1.3)$ & Psychic effects & $9(1.0)$ \\
\hline Social problems & $10(1.1)$ & Social problems & $29(3.2)$ \\
\hline Death & $13(1.4)$ & Death & $2(0.2)$ \\
\hline Criminal activity & $227(25.1)$ & Criminal activity & $21(2.3)$ \\
\hline Traffic accidents & $113(12.5)$ & Addiction & $57(6.3)$ \\
\hline Negligent harm & $2(0.2)$ & Foetus jeopardizing & $2(0.2)$ \\
\hline Victimization & $11(1.2)$ & Combination of health and social problems & $21(2.3)$ \\
\hline Total & $903(100.0)$ & Total & $903(100.0)$ \\
\hline
\end{tabular}




\begin{tabular}{|c|c|c|c|c|c|c|}
\hline & & Harm Evaluation Criteria & & & Czech Media**) (\%) & difference (\%) \\
\hline \multirow{9}{*}{ to users } & \multirow{4}{*}{ Physical } & Drug-s pecific mortality & & 3.5 & 2.2 & -1.3 \\
\hline & & Drug-related mortality & & 5.2 & 0.3 & -4.9 \\
\hline & & Drug-specific damage & & 4.5 & 3.7 & -0.8 \\
\hline & & Drug-related damage & & 4.5 & 11.4 & 6.9 \\
\hline & \multirow{3}{*}{ Psychological } & Dependence & & 2.4 & 9.1 & 6.7 \\
\hline & & Drug-specific impairment of mental functioning & & 5.2 & 2.0 & -3.2 \\
\hline & & Drug-related impairment of mental functioning & & 4.9 & 2.5 & -2.4 \\
\hline & \multirow[t]{2}{*}{ Social } & Loss of tangibles & & 1.7 & 0.0 & -1.7 \\
\hline & & Loss of relationships & & 3.8 & 1.7 & -2.1 \\
\hline \multirow{7}{*}{ to others } & Phys.+Psycho. & Injury & & 16.0 & 19.3 & 3.3 \\
\hline & \multirow{6}{*}{ Social } & Crime & & 7.3 & 42.8 & 35.5 \\
\hline & & Environmental damage & & 5.2 & 0.0 & -5.2 \\
\hline & & Family adversities & & 12.5 & 4.9 & -7.6 \\
\hline & & International damage & & 1.0 & 0.0 & -1.0 \\
\hline & & Economic cost & & 17.7 & 0.2 & -17.5 \\
\hline & & Community & & 4.5 & 0.0 & -4.5 \\
\hline & & Total & & 100 & 100 & \\
\hline
\end{tabular}

Fig. 1. Comparison of the media coverage of harmful effects of alcohol use categorized according to the Independent Scientific Committee of Drugs (33).

ISCD - Independent Scientific Committee od Drugs

${ }^{*}$ ISCD expert scoring for Drug = Alcohol (expressed as a \% of the total alcohol score ower all of the criteria)

${ }^{* *}$ The number of explicit references to this harm in our dataset (expressed as a $\%$ of all the references to all the types of harm)

According to the ISCD, the third most serious aspect (score: $12.5 \%$ ) is a dysfunctional family environment, economic needs and negative impact on the development and upbringing of children. However, this aspect takes the fifth place in the Czech media (4.9\%), which is much less often than it should be if it were to correspond to its true significance. In contrast, the most frequent issue in the Czech media was that of crime (42.8\%), which ranked only in the fourth place in the ISCD classification (7.3\%). Here the difference was the most striking $(35.5 \%)$.

\section{DISCUSSION}

The objectives of this study were to assess to what extent the media portrayal of the effects of alcohol use in the Czech Republic reflects the real burden (or in other words how well the media provide public with evidence-based information on main risks associated with drinking alcohol), and to describe the characteristics of the media portrayal of alcohol.

Prior to our study, the portrayal of alcohol in the Czech media was detailed in two studies of Kováčová (28) in 2005 and Noga (29) in 2012, which were part of broader studies of the media portrayal of various addictive substances. In our dataset, roughly one third (36.88\%) of articles mentioning alcohol have a traffic accident as a theme. Kováčová finds a similar percentage, 33.95\%, in her dataset from 2003, while for Noga in his dataset from 2007 comes to $8.49 \%$ only. He points out that police statistics do not explain the disproportion, and he speaks about different media coverage of this topic in 2003 and 2007. The official police sources (44) show the same trend also for the year of our dataset (the number of accidents, the number of deaths in them, and even the mortality rates are still permanently decreasing). Our explanation is that, besides different media coverage, the surprisingly low number of traffic accidents observed in Noga's dataset may come from a different evaluation method (he draws certain statistics from a health-related subset and not from the whole dataset) or even more likely from the coding method: for example, the articles which linked a traffic incident to alcohol by just mentioning that "there was no alcohol in the driver's blood" or that "the breath test was negative" may have been scored in a different way in the two studies or they may have escaped the primary selection criteria in one of them.

Our results (from 2017) show that the most frequent roles played by alcohol in the Czech media were connected to crime, violence $(44.9 \%)$, health threats $(13.8 \%)$ and addiction, illness (13.3\%), while for Kováčová (28) they were crime, violence $(72.5 \%)$, society threats $(35.6 \%)$ and health threats $(18.1 \%)$ in 2003 , and for Noga (29) they were health threats $(64.60 \%)$, addiction, illness (47.79\%) and bad habit (19.47\%) in 2007. Our results also show addiction (29.4\%), health problems $(27.3 \%)$ and social problems $(14.9 \%)$ as the most medialized long-term usage effects while for Kováčová (28) these were health problems $(38.7 \%)$, social problems $(19.3 \%)$ and death $(16.8 \%)$, and for Noga (29) health problems (33.78\%), social problems (24.32\%) and mental health effects $(21.17 \%)$. Given that the long-term use effect "addiction" was falling under health or social problems in Kováčová and Noga studies $(28,29)$, our final conclusion is that the media portrayal of alcohol usage effects has remained quite stable in the Czech Republic for the last 14 years. When we compare this portrayal to the alcohol harm evaluation by the Independent Scientific Committee of Drugs (33) we detect the following disproportions:

Some issues, such as the economic burden on individuals and society, are neglected in the Czech media, although they were evaluated as very serious by the ISCD. Little space was devoted to the dysfunctional family environment of users and the impact of alcohol on health. There was lack of information on environmental damage and community harm due to the loss of reputation and 
social cohesion. On the other hand, alcohol use effects in the areas of crime and road safety are over-represented in the Czech media.

Our study is limited by four factors: time span, the number of coders, the focus being restricted to harms, and the uneven reach of media (media range was not reflected in calculations). The research contained an analysis of all the articles published in the period of about one month within a year. It could be assumed that the amount of alcohol reports and their character would fluctuate during the year according to events that are traditionally associated with higher alcohol consumption and are typical for the particular periods (42). For a more complex study, it would be interesting to cover two or three times segments with different alcohol consumption patterns (13). This time it was not possible for capacity reasons. The inter-reliability of coding was not applied, so there was no objectivization of categories (subjective judgements may have appeared e.g. when deciding which intoxication effect was the most highlighted one or which theme was the main one). There is an ongoing public and/or media discussion about the possible positive effects of alcohol use. In our comparison we evaluated only the negative ones. Our dataset contained articles from both the local and the nationwide media. However, we did not investigate how numerous a target audience each of them had.

One of inputs for our comparison was a general expert analysis and it would be also interesting to evaluate and compare real data on various harm types from a corresponding period. Further research could also use other data selection strategies to get representative data sample of a longer time period.

\section{CONCLUSIONS}

The medialization of alcohol-related harms is not proportional to their actual severity. The research revealed a significant disproportion in the frequency that alcohol has been referred to as a criminal problem (often traffic related problem) over health and social issues (including the economic cost). The latter is addressed in the media rather insufficiently.

To sum it up, the image of alcohol in the Czech media is rather distorted. We would need to be better informed on the health and social effects of alcohol use. Alcohol abuse is only seldom described as a health issue. The attention is mostly drawn to legal or criminal aspects. Space for interventions that could help increase the general awareness of the harms associated with drinking alcoholic beverages exists. It is recommended that health and addiction prevention professionals present their views in the media more often. Also some basic data like the total social cost of alcohol and their structure (45) are worth to appear in the media more often.

\section{Acknowledgement}

The article has been written as a part of the project Development of the alcohol-focusing activities of the Public Health Centre of the Department of Addictology, First Faculty of Medicine, Charles University and General University Hospital in Prague, Czech Republic and the National Institute of Public Health under the decision to grant a special-purpose noninvestment contribution from the state budget of the Czech Republic to directly managed organizations of the Ministry of Health of the Czech Republic (No. OZS/45/4141/2018) and by the institutional support programme Progress No. Q06/LF1.

\section{Conflict of Interests}

None declared

\section{REFERENCES}

1. GBD 2016 Alcohol Collaborators. Alcohol use and burden for 195 countries and territories, 1990-2016: a systematic analysis for the Global Burden of Disease Study 2016. Lancet. 2018;392(10152):1015-35.

2. World Health Organization. Global Health Observatory data repository: alcohol - data by country [Internet]. WHO; 2018 [cited 2018 Aug 31]. Available from: http://apps.who.int/gho/data/view.main.1800.

3. Ván̆ová A, Skývová M, Csémy L. Alcohol and tobacco use in the Czech Republic 2016 [Internet]. Prague: NIPH; 2017 [cited 2019 Dec 12]. Available from: http://www.szu.cz/uploads/documents/szu/aktual/uzivani_tabaku_2016_konecny_17_7.pdf. (In Czech.)

4. Government of the Czech Republic. Long-term program of improving the health status of the population of the Czech Republic - Health for All in the 21st Century. Government Resolution no. 1046 [Internet]. Prague; 2002 [cited 2018 Sep 10]. Available from: http://irop.mmr.cz/ cs/Zadatele-a-prijemci/Dokumenty/Dokumenty/Ostatni-dokumenty/ Dokumenty-zdravotnictvi/Dlouhodoby-program-zlepsovani-zdravotnihostavu-ob/Usneseni-Vlady-c-1046. (In Czech.)

5. Ministry of Health of the Czech Republic. Health 2020 - National strategy for health protection and promotion and disease prevention. Prague: Ministry of Health of the Czech Republic; 2014.

6. Fagan J, Lyons S, Smyth BP. Content analysis of newspaper reports on alcohol-related deaths. Alcohol Alcohol. 2014;49(4):479-83.

7. Room R, Babor T, Rehm J. Alcohol and public health. Lancet. 2005;365(9458):519-30.

8. Macnamara JR. Mass media effects: a review of 50 years of media effects research [Internet]. CARMA International; 2003 [cited 2019 Dec 12]. Available from: http://citeseerx.ist.psu.edu/viewdoc/download?doi $=10.1 .1 .602 .7475 \&$ rep $=$ rep $1 \&$ type $=$ pdf.

9. Macnamara JR. Media content analysis: its uses, benefits and best practice methodology. Asia Pac Public Relat J. 2005;6(1):1-34.

10. Schiavo R. Health communication: from theory to practice. San Francisco: Jossey-Bass; 2013.

11. Gunter B, Hansen A, Touri M. Impact of alcohol representation in the news. In: Gunter B, Hansen A, Touri M. Alcohol advertising and young people's drinking. London: Palgrave Macmillan UK; 2010. p. 150-170.

12. Slater MD, Long M, Ford VL. Alcohol, illegal drugs, violent crime, and traffic-related and other unintended injuries in US local and national news. J Stud Alcohol. 2006;67(6):904-10.

13. Nicholls J. UK news reporting of alcohol: an analysis of television and newspaper coverage. Drugs (Abingdon Engl). 2011;18(3):200-206.

14. Lancaster K, Hughes CE, Spicer B, Matthew-Simmons F, Dillon P. Illicit drugs and the media: Models of media effects for use in drug policy research. Drug Alcohol Rev. 2011;30(4):397-402.

15. Mercille J. Media coverage of alcohol issues: a critical political economy framework - a case study from Ireland. Int J Environ Res Public Health. 2017;14(6):650. doi: 10.3390/ijerph14060650.

16. Babor TF, Babor T, Caetano R, Casswell S, Edwards G, Giesbrecht N, et al. Alcohol: no ordinary commodity: research and public policy. Oxford: Oxford University Press; 2010.

17. Smith LA, Foxcroft DR. The effect of alcohol advertising, marketing and portrayal on drinking behaviour in young people: systematic review of prospective cohort studies. BMC Public Health. 2009;9:51. doi: 10.1186/1471-2458-9-51.

18. Belackova V, Stastna L, Miovský M. 'Selling by drugs': Content analysis of the coverage of illicit drugs in different news media types and formats. Drugs (Abingdon Engl). 2011;18(6):477-89.

19. Connolly GM, Casswell S, Zhang JF, Silva PA. Alcohol in the mass media and drinking by adolescents: a longitudinal study. Addiction. 1994;89(10):1255-63.

20. Harding K, Watson SL. "Just a little bit": a television media analysis of alcohol consumption during pregnancy. Int J Qual Methods. 2018;17(1):134. doi: https://doi.org/10.1177/1609406918801621.

21. Curtis BL, Lookatch SJ, Ramo DE, McKay JR, Feinn RS, Kranzler HR. Meta-analysis of the association of alcohol-related social media use with alcohol consumption and alcohol-related problems in adolescents and young adults. Alcohol Clin Exp Res. 2018;42(6):978-86. 
22. Hilton S, Wood K, Patterson C, Katikireddi SV. Implications for alcohol minimum unit pricing advocacy: what can we learn for public health from UK newsprint coverage of key claim-makers in the policy debate?. Soc Sci Med. 2014;102:157-64.

23. Wilson I, Munro G, Hedwards B, Cameron S. A historical analysis of alcohol advertising in print media 1989-2009. Carlton: Victorian Health Promotion Foundation; 2012.

24. Baillie RK. Determining the effects of media portrayals of alcohol: going beyond short term influence. Alcohol Alcohol. 1996;31(3):235-42.

25. Hansen A, Gunter B. Constructing public and political discourse on alcohol issues: towards a framework for analysis. Alcohol Alcohol. 2006;42(2):150-7.

26. Lemmens PH, Vaeth PA, Greenfield TK. Coverage of beverage alcohol issues in the print media in the United States, 1985-1991. Am J Public Health. 1999;89(10):1555-60.

27. Azar D, White V, Bland S, Livingston M, Room R, Chikritzhs T, et al. 'Something's brewing': the changing trends in alcohol coverage in Australian newspapers 2000-2011. Alcohol Alcohol. 2013;49(3):336-42.

28. Kováčová K. Alcohol usage and users in context analysis of media reports [dissertation]. Olomouc: Palacký University Olomouc; 2005. (In Czech.)

29. Noga M. Health effects of using alcohol in context content analysis of media reports [dissertation]. Olomouc: Palacký University Olomouc; 2012. (In Czech.)

30. Office of the Government of the Czech Republic. Drugs in the media. Focused on Drugs. 2006;(3):1-8. (In Czech.)

31. Office of the Government of the Czech Republic. Media images of drugs in the European Union. Focused on Drugs. 2007;(1):1-12. (In Czech.)

32. Mravčík V. Epidemiology of problem drug use [dissertation]. Prague: Charles University; 2018. (In Czech.)

33. Nutt DJ, King LA, Phillips LD. Drug harms in the UK: a multicriteria decision analysis. Lancet. 2010;376(9752):1558-65.

34. Best D, Gross S, Vingoe L, Witton J, Strang J. Dangerousness of drugs: a guide to the risks and harms associated with substance misuse. London: National Addiction Centre, Department of Health; 2003.

35. Van Amsterdam J, Opperhuizen A, Koeter M, van den Brink W. Ranking the harm of alcohol, tobacco and illicit drugs for the individual and the population. Eur Addict Res. 2010;16(4):202-7.
36. Taylor M, Mackay K, Murphy J, McIntosh A, McIntosh C, Anderson $\mathrm{S}$, et al. Quantifying the RR of harm to self and others from substance misuse: results from a survey of clinical experts across Scotland. BMJ Open. 2012;2(4):e000774. doi: 10.1136/bmjopen-2011-000774.

37. Degenhardt L, Hall W, Warner-Smith M, Lynskey M. Illicit drug use. In: Ezzati M, Lopez AD, Rodgers A, Murray CJL, editors. Comparative quantification of health risks: global and regional burden of disease attributable to selected major risk factors. Geneva: WHO; 2004. p. 1109-76.

38. Zábranský T. Drug epidemiology. Olomouc: Palacký University Olomouc; 2003. (In Czech.)

39. Hsieh HF, Shannon SE. Three approaches to qualitative content analysis. Qual Health Res. 2005 Nov;15(9):1277-88.

40. Bryman A. Integrating quantitative and qualitative research: how is it done? Qual Res. 2006;6(1):97-113.

41. Newton Media. NewtonOne [Internet]. Prague: Newton Media [cited 2019 Apr 22]. Available from: https://www.newtonmedia.cz/en.

42. Petruželka B, Barták M, Rogalewicz V, Popov P, Gavurová B, Dlouhý M, et al. Alcohol use and related problems among students of social work at selected universities in the Czech Republic and Slovakia - a pilot study of the risky periods. Adiktologie. 2017;17(2):108-17. (In Czech.)

43. Št'astná L, Miovský M, Novák P. Manual for coding of media messages on addictive substances and related issues: user's handbook. Tišnov: Sdružení SCAN; 2009

44. Straka J, Fabianova J. Yearbook of accident on ground communications in the Czech Republic per year 2017 [Internet]. Prague: Traffic Police Service Directorate of the Police Presidium of the Czech Republic; 2018 [cited 2019 Dec 12]. Available from: https:/www.policie.cz/clanek/ statistika-nehodovosti-900835.aspx. (In Czech.)

45. Zábranský T, Běláčková V, Štefunková M, Vopravil J, Langrová M. Social costs of alcohol, tobacco and illicit drug use in the Czech Republic in 2007. Prague: The Department of Addictology, Psychiatric Clinic, First Faculty of Medicine, Charles University in Prague and General University Hospital in Prague; 2011. (In Czech.)

Received May 22, 2019

Accepted in revised form December 11, 2019 